the parasite. This is apparcntly the view which Koch has taken of the action of his tymph. The action of the product on the tissues is, however, of the same kind as that of the substances used in some of the methods already mentioned, but more intense, and Koch's views will probably have to be modified.

In this attempt to analyse the methods which have been proposed I have separated processes many of which may act concurrently. This is, however, of little consequence, for my object was less to give an account of any single method than to trace the development of the ideas which are at the basis of the treatment of bacterial diseases. In this way I hope I may have been able to show you bow science prepares the way for the highest branches of the art-viz., preventive, protective, and curative medicine.

\section{HODGKIN'S DISEASE; PYREXIA; SUDDEN DEATH, WITH COPIOUS SANGUINEOUS EFFUSION INTO THE LUNG.}

By HARRINGTON SAINSBURY, M.D., M.R.C.P., SENIOR ASSISTANT PHYSICIAN TO THE VICTORIA-PARK HOSPITAL FOR CHEST DISEASES ; PHYSICIAN TO THE ROYAY FREE HOSPITAL.

THE following case is of interest on account of its somewhat puzzling nature during life, but more particularly on account of its very unusual mode of ending. The patient was admitted under Dr. Thorowgood, but she was subsequently seen by me during his absence; it is at his kind request that I place the case on record.

Annie A-, aged eighteen, single, a matchbox maker by occupation, was admitted in to the Victoria-park Hospital on Aug. 7th, 1890. She complained of pain in the left hypochondrium and of weakness. She stated that she had been ill four weeks suffering from feverishness and weakness; for three days there had been headache; the bowels had been rather constipated during the whole period, acting some two to three times a week. There had been slight pain in the lower part of the abdomen; she had never vomited. On admission, there were a flushed face, hot skin, and dry glazed tongue, showing posteriorly a little fur. The temperature was $101 \cdot 2^{\circ}$; pulse 114 , and of low tension. The abdomen was normal in appetrance, there was no tenderness, but the spleen projected one inch and a quarter below the costal margin. There were no symptoms pointing to thechest, neither cough nor expectoration, and the physical signs were negative for both heart and lungs. In the neck the glands were enlarged, especially on the right side in the supra-clavicular region; but they were not conspicuous, and though the enlargement was decided, they were to be felt rather than seen. There was slight enlargement of the glands in the axillæ and in the right groin. The enlarged glands were hard, well-defined, and freely movable. The urine was acid; sp. gr. 1010, and free from albumen. In the absence of any definite symptoms-diarrhœa, spots, \&c.,-but in the presence of the fever and the enlarged spleen, the patient was put on typhoid treatment, and, so far as the diet was concerned, this treatment was maintained for some time after it had become clear, from the temperature curve, that the case was not one of enteric fever. The patient was examined on several occasions up to the time of her death, which occurred quite suddenly and unexpectedly, but no fresh signs developed. On Aug. 14th the spleen showed slight increase in size, and some scybalous freal accumulation in the descending colon was noted. Throughout the bowels were rather constipated, and in the early stages glycerine enemata were required. On Sept. 12th the glands on the right side of the neck above the clavicle were larger. On the 20 th the glands in the left infra-maxillary region were enlarged, but the spleen had diminished somewhat. On Oct. lst the spleen was again somewhat larger. Death occurred on Oct. 2nd.

In the chest some creaking sounds were heard near the angle of the right scapula on Sept. 27th, and on Oct. 1st the note under the left clavicle was doubtfully impaired. On this date a systolic bruit was heard at the base of the heart. Nothing more definite was discovered in the chest. On the two occasions that the blood was examined it was found to contain 75 per cent. of the normal corpuscular richness and no excess of white cells. The amount of hæemoglobin was unfortunately not estimated. The temperature curve was very interesting. There was fever the whole of the eight weeks during which the patient was in hospital; it was, however, markedly remitting, the lowest records falling just above or just below $99^{\circ} \mathrm{F}^{\circ},\left(98 \cdot 8^{\circ}\right.$ and $986^{\circ}$ were frequent records) On six occasions only did the curve touch $98.4^{\circ}$ or dip just below it. The maximal temperatures were $102^{\circ}, 101^{\circ}, 100^{\circ}$; on two occasions $1028^{\circ}$ was reached. The remissions and exacerbations were very regular, the former taking place about 8 A.M., the latter between 8 and 12 P.M. The range of temperature was about $4^{\circ}$ during the first week, about $3^{\circ}$ during the second week, and about $2^{\circ}$, or a little over, during the third week. During the fourth week the temperature was at its lowest, and the pyrexia appeared to be gradually breaking up ; but in the fifth week the range again increased, and it mounted still more during the fol. lowing three weeks, averaging $3^{\circ}$ to $4^{\circ}$. If to the bospital period we add the four weeks of feverishness, of wbich she gave the history on admission (she had been on milk diet for two weeks before admission), we have a total period of three months of pyrexia. In spite of this prolonged pyrexia, the patient did not seem seriously ill ; so little, in fact, that it was thought well to allow her to get up to tea in the last days of September, and according to her own statement she felt better. On Oct. 1st the last examination was made, with practically negative results. The enlarged spleen and lymphatic glands were the only positive signs.

Mode of death. - At about 2.10P. M. the patient went to sleep afterdinner, and nothing unusual was noticed until 3.30 P.M, when the nurse's attention was directed to her. The head and neck were then rigid, and the eyes fixed in an upward direction. There was slight turgescence of the face; no cry was uttered. There was no evidence of blood in the mouth either immediately before or after death. Five sighing respirations took place, and death happened in about thirty secunds.

I unfortunately could not be present at the necropsy, but the following is the post.mortem record by Dr. Ruffer, the pathologist to the hospital : - Body emaciated ; staining well marked; rigor mortis well marked. In the pericardium about half a pint of clear serum. The left lung adherent everywhere by white adhesions; soft over the greater part of the lung, but tough behind ; at the back part the lung was torn during removal ; the lower lobe filled with blood, which oozes from every pore, so that the whole lung looks like currant jelly; portions excised sink in water; the upper lobe normal; the bronchial glands not increased. The right lung normal, except at the base, where there has been a much less extensive but similar hæmorrhage to that on the left side; no adhesions on this side. The spleen red, $22 \mathrm{oz}$. in weight; no infarcts; its substance was highly coloured, but fairly hard. The retro-peritoneal glands larger than natural ; some attain the size of a walnut. The liver $59 \mathrm{oz}$. in weight; smooth; tough. The kidneys very large, tough, and firm. The intestines healthy. The pancreas healthy.

Remarks. - As to diagnosis little need be said. It is true that in the first stage some hesitation as to the possibility of typhoid was felt, but this was abandoned later upon studying the temperature curve, and the pyrexia was referred to the enlarged Jymphatic glands and spleen in the absence of any other lesion-the case being diagnosed as one of lymphadenoma or Hodgkin's disease. The tempera. ture curve corresponded with the third or remittent type of pyrexia described by Gowers as occurring in lymphadenoma; the other types met with, according to this authority, being the continuous and the alternating types. Pyrexia is of course not a necessary feature of the disease, but this case accords with Gowers' statement that there is fever in nearly all cases under twenty years of age. The absence of much pallor helped to mask the case, nor did the microscope give any very striking proofs of anæmia; the observations on this point were, however, too few to base any conclusions upon, and the hæmoglobin percentage was not estimated. We may, however, mention the fact, according to Gowers, that glandular enlargement may occur and advance before any signs of deficient blood formation present themselves. Real anæmia may be present even to the extent of a reduction of the red cells to 60 per cent., whilst the face is well coloured. The urine was not watched, but the note on admission records a specific gravity of 1010 and the absence of albumen. As to the mode of deatb, this is, I believe, very unusual. Gowers mentions hæmorrhage from the nose and mouth 
as a cause of death in one case. Birch-Hirschfeld ${ }^{2}$ wites of a tendency to profuse hremorrhage from nose and mouth, but he gives no details. Coupland ${ }^{3}$ mentions biemorrhage as less common in lymphadenoma than in leukæmia and pernicious anæmia But I have not been able to come across a case quite similar to this. That the lungs should to a great extent fill with blood without the appearance of any blood in the mouth seems astonishing, and the only explanation for this, at all plausible, seems the-suddenness with which death took place. I understand that at the necropsy the main bronchi did not show any blood in their lumen. Was it really a hæmorrhage or an acute sanguineous œdema? In either case the sudden death in association with this remarkable condition of lungs is surely worth recording.

Welbeck-street, W.

\section{HAMORRHOIDS.}

CAN OPERATIVE INTERFERENCE BE AVOIDED BY EFFICIENT MEDICAL TREATMENT ADOPTED IN TIMH?

By W. R. T H O A S, M. D., M. R. C. P.,

LATE LECTURER ON MEDICINE, SHEFFIELD MEDICAL SCHOOL; CON SULTING PHYSICIAN TO THE SHEFFIELD PUBLIC HOSPITAL

For many years I have felt very confident that the majority of cases of hæmorrhoids we meet with, some of which we treat with medicine, others by operation, are entirely preventable, and that many of those even which are far advanced can be cured by medical treatment alone, but it is necessary when treating them to give due consideration to all the causes, and to treat each one. I have found during the last few years, when $I$ have met with a patient willing entirely to submit to medical treatment, that such treatment has always been a success; but unfortunately the majority of patients are self-indulgent, and quite wanting in perseverance; and in such cases treatment, because incomplete, is often a failure. In my remarks I refer to both internal and external hæmorrhoids, but more particularly to the internal. I select three out of the last sixty cases I have had to deal with as fair examples of all.

CASE 1.-A gentleman, aged forty, anæmic, great debility, functional cardiac symptoms, \&e. He has suffered from internal hæmorrhoids for six years, with frequent hæmorrhage when at stool, the mass, when protruded, being the size of a small orange. Cause : sedentary life, laziness, constipation. Treatment: Daily walk insisted on, more vegetable food, friction to abdomen, white mixture or Esculap in the morning when require local sponging. After three months' treatment he was quite well.

CASE 2.-This patient, a female, has had six children; very weak; hæmorrhoids for years, which now protrude at each evacuation and bleed, causing anæmia. Treatment: Daily walks, more vegetable food, white mixture when required, injections of lukewarm water at first, and then cold water, local applications of cold every morning. At the end of two months there was no protrusion at all when at stool; no local discomfort whatever; quite well.

CASE 3.-The patient, a male, aged forty-two, stout and florid, is a heavy drinker and eater. Liver and abdomen enlarged; he suffered from hæemorrhoids for the last four years; they protrude, bleed, and are about the size of a small orange. Hæmorrhoids always worse after drinking. Cause: Excess in eating and drinking, want of exercise, constipation. Treatment: Abstinence from drink, almost total; injections of cold water every morning. White mixture when required. Local applications of cold.

There are a number of factors which have to do with the production of hæmorrhoids which it would be well for us to remember, as it is only by considering each one which has helped to bring on the disease that we can hope to effect a cure. These are : the valveless condition of the portal veins, gravitation, obstruction owing to hepatic disease, obstruction from heart or lung disease, sedentary habits, excessive eating and drinking, straining from any cause, excessive obesity, and taking purgatives too frequently. Owing to the valveless condition of the veins, there is not any propulsion forwards from the contraction of thesurrounding tissues, and a congested condition of the radicles of the portal veins is the result, giving rise, perhaps, ultimately to hremorrhoids. Gravitation will tend to inorease the size of the lowest veins. Obstructions from liver, heart, or lungs will have the same effect. Sedentary habits induce a diseased condition of the liver, with consequent obstruction to the passage of portal blood through it. The abdominal muscles do not, by their contractions, assist in propelling the contents of the intestines forwards, a constipated condition of bowels and dilated state of veins being thus produced. Excessive eating or drinking produces disease of the liver, obesity, and other injurious consequences. Straining at stool from any cause is a factor of importance; for the pressure brought to bear upon the intestines generally, by the abdominal muscles, diaphragm, and other muscles, tends to produce a very dilated condition of the lowest vessels, those of the rectum, which, often during the act of defecation, give way and hæmorrhage ensues. Excessive obesity aggravates, by its pressure, this tendency to congestion. Many people are in the habit of taking purgatives daily. They do not seem to appreciate, or to be aware of the fact, that ordinarily only a certain amount of fæcal matter, that which is in or near to the rectum, should be expelied daily; and that if, by taking purgatives, several feet of intestine be evacuated, proper purgation cannot be expected the next day; time must be allowed for reasonable accumulation, witich will generally be a sufficient stimulus to the whole intestinal canal. Now when treating hæmorrhoids, I believe that if we take into consideration and treat each one of the several causes we shall often meet with most satisfactory results. Many of the recommendations appear to be trivial; but success very frequently follows attention to them, and operative treatment follows neglect of them.

Daily action of bowels. - Owing to hurry many sadly neglect the bowels, which act very irregularly. It is very important that they should be trained to act once a day from childhood, say, immediately after breakfast, and those who have paid proper attention to this rule but seldom require treatment. Sponging the anus and surrounding parts with soap and cold water is a very efficient application. Acrid fluids \&c., which during the ensuing day would irrita te the skin, are removed.

Diet ac. - In this country we, as a rule, eat far too much meat and too little vegetable food. I am confident that this habit has much to do with the costive state of bowels and the formation of hæmorrhoids. I have seen cases of hæmorrhoids with constipation cured by such attention alone, by taking apples or pears after breakfast, by increasing the quantity of cabbage, cauliflower, \&c., taken with dinner and with luncheon, and by at the same time diminishing the amount of meat eaten.

Exercise. - I believe that this is a most important cause, and that if a reasonable amount of physical exertion were undergone by the nation generally, constipation and hæmorrhoids would very seldom require treatment, the liver would be well kneaded daily, inspissated bile would be propelled, and the action of the intestines would be assisted by the abdominal muscles.

Injections.-It is astonishing how much relief some patients obtain by an injection daiiy of as much water as can be retained for four or five minutes with comfort. I generally begin by recommending lukewarm water, but as soon as the patient can bear cold I order it. This seems to stimulate the whole bowel from above downwards, to act as a tonic on its interior by daily removing large masses which lodge in the rectum, to enable its walls to regain their elasticity and contractility, and by removing irritating secretions and pressure, to prevent hyperplasia of cellular tissue which accompanies a dilated condition of veins.

Alcohol.-Those who suffer from hæmorrhoids should, if possible, give up taking stimulants entirely; for they tend to produce a dilated condition of vessels everywhere, and by causing disease of the liver of an obstructive character give rise to dilatation of all the small branches of the vena porta, and those of the rectum suffer more than any.

I may here repeat what I have already said, that nearly all cases of hrenorrhoids, both internal and external, can be cured by proper, simple, rational medical treatment. Bournemouth 